\title{
El Músico Argentino Adolfo Reisin y las Estéticas de la Improvisación Colectiva
}

\section{The Argentinian Musician Adolfo Reisin and the Aesthetics of Collective Improvisation}

\author{
Daniel Moro Vallina \\ Afiliación (Universidad de Oviedo, Oviedo, Asturias, España) \\ morodaniel@uniovi.es
}

Resumen: El presente artículo plantea una aproximación a la figura del músico argentino Adolfo Reisin (1936-2020), aún desconocido para el gran público y la comunidad musicológica. En primer lugar, se profundiza en el trabajo de Reisin para el medio teatral en la Argentina de la década de 1960, donde formó parte del movimiento del Teatro de los Independientes. A continuación, se analizan las influencias internacionales que configuraron su estética (Pierre Schaeffer, Luigi Nono e Iannis Xenakis, entre otros) y cómo estos nombres contribuyeron a la evolución de Reisin hacia la libre improvisación colectiva y la experimentación con la voz. Su principal aportación en este campo fue el llamado "solfeo corporal-gestual", una técnica propia que implica aspectos no solo artísticos, sino también pedagógicos y musicoterapéuticos. A través del análisis de fuentes provenientes de su archivo personal (documentos autobiográficos, críticas de prensa y videograbaciones de sus talleres de improvisación) y de entrevistas personales realizadas al autor estudiamos la trayectoria estética de Reisin poniéndola en relación con otras propuestas internacionales vinculadas a la libre improvisación (particularmente, el Gruppo di Improvvisazione Nuova Consonanza). Se concluye afirmando que el tipo de improvisación que Adolfo Reisin desarrolló a lo largo de su carrera estuvo influida tanto por su formación inicial en el teatro como por su interés en la renovación

\footnotetext{
1 Este artículo se enmarca en el Proyecto de Investigación "Música en España y el Cono Sur Americano: transculturación y migraciones (1939-2001)", financiado por el Ministerio de Ciencia e Innovación de España (MCI-20-PID2019-108642GB-I00). El autor forma parte asimismo del Grupo de Investigación en Música Contemporánea de España y Latinoamérica (GIMCEL), coordinado por la Universidad de Oviedo.
} 
de los modelos pedagógicos de la enseñanza musical (especialmente aquellos dirigidos a la primera infancia).

Palabras clave: Música Argentina. Improvisación. Teatro. Expresión Corporal. Pedagogía Musical.

Abstract: This article deals with the Argentinian musician Adolfo Reisin (1936-2020), a figure still unknown both to the public and the musicological community. The first objective of the article is to go in depth into Reisin's work for theatre in Argentina during the 1960s, where he was part of the movement known as Teatro de los Independientes. A second objective takes into consideration the main international composers that influenced his aesthetic -mainly, Pierre Schaeffer, Luigi Nono and Iannis Xenakis-, and how they contributed to Reisin's particular evolution to collective free improvisation and the experimentation with voice. Reisin's main contribution in this field was the so-called "corporalgestural solfeggio", a technique of his own that involves both artistic, pedagogical and music therapy facets. The study of Adolfo Reisin's aesthetic trajectory is carried out through the analysis of the author's own archival sources (autobiographical documents, press articles and video recordings of some of his music improvisation workshops) as well as personal interviews with him, connecting his career with the work of other free improvisation groups such as the Gruppo di Improvvisazione Nuova Consonanza. The main conclusion of the article is that the kind of improvisation developed by Adolfo Reisin was influenced both by his initial training in musical theatre and by his interest in the renewal of the pedagogical models of music teaching: especially, those aimed at early childhood.

Keywords: Argentinian Music. Improvisation. Theatre. Body Expression. Musical Pedagogy.

Submetido em: 1 de junho de 2021

Aceito em: 8 de julho de 2021 
El Músico Argentino Adolfo Reisin y las Estéticas de la Improvisación Colectiva Daniel Moro Vallina

\section{Introducción}

El nombre del compositor, director, pedagogo e improvisador Adolfo Reisin (Buenos Aires, 4 de enero de 1936-Gijón, 24 de diciembre de 2020) permanece en gran parte desconocido tanto para la musicología argentina como para la de ámbito internacional. Exceptuando algún trabajo de índole divulgativa (MORO, 2015), no existen estudios que aborden su trayectoria creativa y la contextualicen en el panorama de la música contemporánea de la segunda mitad del siglo XX. Y, sin embargo, las múltiples facetas que caracterizaron su carrera y su presencia en importantes escenarios latinoamericanos y europeos nos hablan de una actividad lo suficientemente rica como para trazar esta primera y necesaria aproximación.

Dicha actividad se inició en su ciudad natal a comienzos de 1960 formando parte del Ilamado Teatro de Los Independientes, donde Reisin dirigió la música de varias obras teatrales de Bertolt Brecht en un momento de especial efervescencia política y cultural (VERZERO, 2013). Durante 1966 integró el Groupe de Recherches Musicales fundado en París por Pierre Schaeffer; en 1967 visitó el Instituto Torcuato di Tella y puso música a algunas propuestas experimentales de teatro-danza como Apocaliptosis o Danza Ya, esta última en colaboración con la coreógrafa Susana Zimmermann (PINTA, 2010; ZIMMERMANN, 2007). A partir de 1977 Reisin se instaló en París para dirigir un programa de didáctica musical destinado a la primera infancia, financiado por el Fondo de Intervención Cultural de Francia. También fue director del Departamento de Pedagogía Experimental del Centro de Asistencia Educativa e Investigaciones (AER) de París, director pedagógico de la Asociación para el Desarrollo de la Música Contemporánea (ADMC) —creada junto al músico Robert Cohen-Solal_, fundador del grupo Temps Réel (música contemporánea y teatro musical) y director del Laboratorio de Experimentación Musical de la Secretaría de Cultura de Roma. Su principal contribución sería el llamado "solfeo corporal-gestual", una técnica propia derivada de las prácticas de la improvisación colectiva 
El Músico Argentino Adolfo Reisin y las Estéticas de la Improvisación Colectiva Daniel Moro Vallina

que aplicó en numerosos talleres celebrados en París, Buenos Aires, Rosario, Río Negro, Río de Janeiro, Machurrucutu (Cuba) Altafulla (Tarragona), Oviedo o Gijón (Asturias). Reisin también se desempeñó como profesor titular de Composición, Música Electroacústica y Música Aplicada en la Universidad Nacional de La Plata (1967-1973), profesor y director del coro del Colegio Nacional de Buenos Aires (1973-1976) y consultor de la UNESCO París en el Área de Educación por las Artes, entre otros cargos oficiales.

Más que glosar las etapas de una vida siguiendo el modelo biográfico convencional, el propósito de este artículo es trazar el perfil estético de Adolfo Reisin como un todo coherente que se desarrolló en empresas aparentemente diversas: el teatro musical, la improvisación experimental y la pedagogía infantil. Estas facetas quedan integradas en su visión de la música como una herramienta de comunicación interdisciplinar capaz de reunir distintas prácticas artísticas; como él mismo declaraba en una de sus primeras entrevistas en prensa, un "arte de confluencias"2. En la actividad de Reisin se refleja igualmente un compromiso político que se manifestó no solo en su interés por difundir el teatro social de Brecht en la Argentina de los años 60, sino también en el hecho de haber militado en el FATRAC (Frente Antiimperialista de los Trabajadores de la Cultura) entre 1968 y 1970, un núcleo de artistas, intelectuales y científicos ligados al PRT que dinamizaron la escena teatral y cinematográfica argentina acercando la vanguardia política a la cultural (TILLET, 2010; CORDA, 2006). Esta estética del compromiso se observa también en su colaboración musical para la ópera Gurka. Las Malvinas en el Hospicio (1988), escrita por Vicente Zito Lema -ex miembro del FATRAC - en torno al tema de la locura producida por la guerra y en la que participaron los internos del sanatorio mental Hospital Borda de Buenos Aires ${ }^{3}$.

Junto a estos aspectos, el objetivo principal del artículo es profundizar en las impresiones que Reisin tenía acerca de la improvisación, contextualizando su enfoque con las aportaciones

\footnotetext{
2 VALLES, Susana. Adolfo Reisin, Los Independientes, y un arte de "confluencias". Hoy en la cultura, Buenos Aires, n. 15, s/p, jul. 1964. Todos los documentos citados a pie de página provienen del archivo personal de Adolfo Reisin.

3 La locura total de la guerra. La razón, Buenos Aires, s/p, 10 dic. 1988.
} 
El Músico Argentino Adolfo Reisin y las Estéticas de la Improvisación Colectiva Daniel Moro Vallina

de algunos estudios recientes sobre esta práctica: la falsa dicotomía entre composición e improvisación (MATTHEWS, 2002; FANTINI, 2014), su definición a partir de teorías filosóficas como la formatividad de Luigi Pareyson (BERTINETTO, 2014), su potencial educativo y sus usos en la musicoterapia (IMBERTY, 2014; BERGSTROMNIELSEN, 2003) o la revisión de algunos mitos como la visión de la improvisación como creación ex nihilo (IRETA, 2019). También nos interesa relacionar el ideario estético de Reisin con otros colectivos de vanguardia contemporáneos a su figura, como el romano Gruppo di Improvvisazione Nuova Consonanza y su principio de "acción-reacción" (TORTORA, 1990; BERTOLANI, 2019). Particular atención merece la noción del solfeo corporal-gestual de Reisin, una propuesta que involucra contenidos no solo artísticos sino también pedagógicos y musicoterapéuticos.

El artículo se divide en tres partes. En la primera abordamos los inicios de Reisin en el ámbito del teatro musical y cómo se gestaron algunos de los rasgos que evolucionarían posteriormente hacia la improvisación colectiva. Una segunda sección está dedicada a este concepto y su puesta en práctica. Por último, en la tercera parte explicamos la vertiente pedagógica de la libre improvisación que Reisin desarrolló en Francia desde finales de los años 70. Para esta investigación hemos podido acceder al archivo personal del músico, que conserva documentación diversa como carteles, folletos de talleres, artículos de prensa y textos autobiográficos. Especialmente relevantes son dos fuentes donde Reisin explica sus ideas sobre la improvisación: un texto de autoanálisis fechado en $1981^{4}$ y la memoria de un proyecto de formación musical llevado a cabo en varias guarderías de París entre 1981 y 19845. También contamos con las propias palabras del autor registradas en una entrevista que le realizamos en $2013^{6}$ y con la videograbación de algunos de sus talleres, en aras de lograr una visión más completa sobre este músico singular que combine fuentes archivísticas, análisis etnográfico e historia oral.

\footnotetext{
4 Documento mecanografiado de 8 páginas, sin título, fechado en Río de Janeiro, junio de 1981.

5 LEDOUBLEE, Suzanne y MEDEDJI, Denise. La musique dans le secteur de la toute petite enfance. Memoria mecanografiada de 168 páginas, inédita y sin fecha.

6 Entrevista realizada el 16 de marzo de 2013 en su domicilio de Gijón.
} 
El Músico Argentino Adolfo Reisin y las Estéticas de la Improvisación Colectiva Daniel Moro Vallina

\section{El Trabajo en el Medio Teatral: Compromiso y Comunicabilidad}

Aunque el inicio de la carrera musical de Adolfo Reisin en Buenos Aires se sitúa a finales de la década de 1950, como fundador de un grupo escénico-coral denominado "Los Juglares del Siglo XX" y escribiendo la música para la versión de Antígona de Jean Cocteau (1959), su verdadero debut vino en 1963 con la obra Concierto para caballero solo de Pedro G. Orgambide, estrenada en el Teatro Payro bajo la dirección de Onofre Lovero y el Teatro de Los Independientes (véase Figura 1). Como señala Lorena Verzero, el TLI se fundó en 1952 por iniciativa de Lovero y fue uno de los grupos en los que se había multiplicado el movimiento del Teatro Independiente, junto a otros colectivos como Nuevo Teatro, La Máscara o Teatro Popular Fray Mocho. En general, todos ellos mostraban un posicionamiento intelectual y político antiperonista que, tras la caída de Perón, se redefinió ideológicamente manteniendo una posición de izquierdas (VERZERO, 2013: 76-78).

Por otro lado, como el mismo Reisin recordaba en un texto autobiográfico inédito7, su integración en el TLI fue prácticamente un producto del azar. Lovero había encargado en un primer momento la música para la obra de Orgambide al argentino Virtú Maragno, quien poco antes del estreno desistió de la empresa. En aquella época formaba parte del elenco del TLI la actriz Ruth Reisin - primera esposa del músico—, y fue así como Lovero pudo conocer y contratar al futuro compositor. Ese mismo año de 1963, Reisin recibiría el premio a la mejor música teatral por La luna en un chal de arcoíris, del dramaturgo jamaicano Errol John y dirigida también por Lovero ${ }^{8}$. Su trabajo fue lo suficientemente prometedor como para que en 1964 se crease un Departamento de Actividades Musicales en el seno del TLI, bajo su propia dirección.

\footnotetext{
7 Texto mecanografiado de 4 folios sin paginar, escrito en Gijón en 2013 ("Asturias, 50 años después"). 8 Talía dio menciones de la temporada del año 1963. El Mundo, Buenos Aires, s/p, 26 dic. 1963. 9 Nuevo organismo musical a cargo del maestro Adolfo Reisin. Ariel, Buenos Aires, s/f.
} 
El Músico Argentino Adolfo Reisin y las Estéticas de la Improvisación Colectiva Daniel Moro Vallina

Figura 1 - Cartel de la obra teatral Concierto para caballero solo (1963).

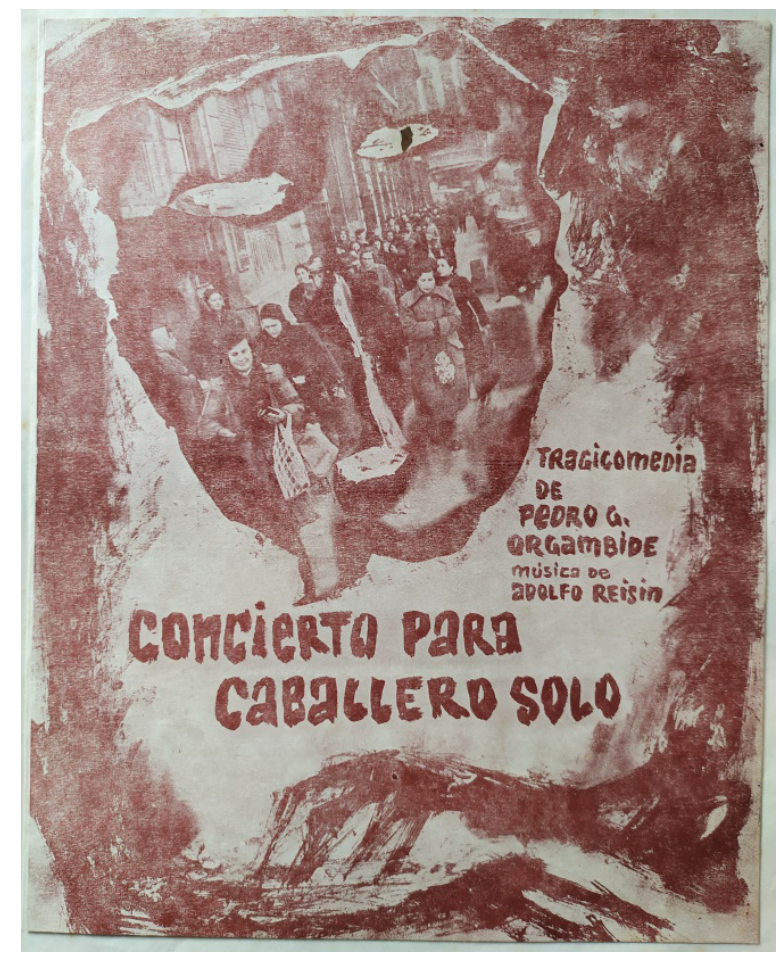

Fuente: Archivo personal de Adolfo Reisin (Gijón, España).

El aspecto más reseñable de esta primera etapa será el conocimiento del teatro de situación de Bertolt Brecht — difundido en Buenos Aires desde 1954-y los modelos de la Kampfmusik o "música de combate" que proponía el compositor alemán Hanns Eisler. Reisin se encargó de la dirección musical de varias obras de Brecht estrenadas en Argentina durante los años 60, como Madre Coraje (Teatro Municipal de Verano, 1964), Santa Juana de los Mataderos (Teatro L.F.T., 1965), Un hombre es un hombre (Teatro de la Fábula, 1965) y especialmente la cantata Galileo Galilei, con música de Eisler (TLI, 1964 y Teatro Peyro, 1966) ${ }^{10}$. El interés de Reisin por este dramaturgo continuaría con la composición musical para una adaptación de varios textos suyos titulada Yo, Bertolt Brecht, digo, estrenada por el Grupo Argentino de Teatro para Todos en junio de 1976; una fecha especialmente relevante si tenemos en cuenta

\footnotetext{
10 La prensa argentina se hizo eco de este importante estreno en los meses de noviembre y diciembre de 1964, tal y como prueban los recortes de prensa que hemos consultado correspondientes a los periódicos La Nación, La Razón, Crónica, La Prensa o la revista Teatro XX. El propio Onofre Lovero consideraba esta empresa como un verdadero reto debido a su complejidad escénica, tal y como declaraba para Teatro XX (recorte titulado "La flagelación por Brecht", sin fecha. Archivo personal de Adolfo Reisin).
} 
El Músico Argentino Adolfo Reisin y las Estéticas de la Improvisación Colectiva Daniel Moro Vallina

el acto de disidencia política que suponía estrenar una obra así en el contexto de la dictadura militar de Videla y el clima de represión que la caracterizón 11 .

Con ocasión de la programación de Galileo Galilei, el TLI publicó un libreto-programa donde figuraba un escrito de Reisin titulado "Música en Brecht". En él expresaba su admiración por los planteamientos estéticos de Eisler respecto al logro de una estrecha unión entre la parte musical y la dramático-teatral:

El aporte de Hanns Eisler a la conformación total del espectáculo es, como se podrá apreciar, de un gran valor, sobre todo para confirmar los hallazgos estéticos y sus enormes posibilidades de desarrollo, del teatro de Brecht, que permite no solo la expansión formal del arte dramático contemporáneo, sino también la evolución del movimiento musical hacia expresiones que confluyen con el color, el espacio y la imagen, en derredor de la idea dramática, en pos del ámbito del espectáculo [...] Esta actitud creadora, iniciada hace ya más de cuarenta años, permanece aún vigente en toda su plenitud en el espíritu de músicos y dramaturgos preocupados intensamente tanto por la búsqueda de nuevos lenguajes de expresión, como por la sustentación de uno de los principios permanentes del hecho artístico: la comunicación humana ${ }^{12}$.

Poco después del estreno, Reisin declararía en la revista Primera Plana lo siguiente: "no acepto la designación música incidental, porque suena demasiado a complemento, a acompañamiento. Creo en la necesidad de reunir las distintas disciplinas del arte en un espectáculo funcional: un arte de confluencias"13. Una opinión similar se recogía en la citada entrevista de Susana Valles: "encuentro en el teatro un vehículo particularmente eficaz para lograr un objetivo primario en la creación artística: la comunicación

\footnotetext{
11 Bertolt Brecht y su oposición al nazismo. La nación, Buenos Aires, s/p, 3 jun. 1976.

12 REISIN, Adolfo. Música en Brecht. Libreto-Programa de Galileo Galilei. Buenos Aires: TLI, s/p.

13 Donde se juntan los caminos. Primera Plana, Buenos Aires, año 3, n. 113, s/p, 5 ene. 1965.
} 
El Músico Argentino Adolfo Reisin y las Estéticas de la Improvisación Colectiva Daniel Moro Vallina

humana"14. De esta forma, Reisin manifestó ya desde el inicio un perfil interdisciplinar que vincula música, danza y acción dramática en un mismo propósito comunicativo. También entonces comenzó a colaborar con la coreógrafa Susana Zimmermann en algunas conferencias y seminarios organizados por el TLI, como la titulada "Improvisación y creación en la danza"15. De esta relación surgirían luego propuestas de improvisación colectiva llevadas a cabo en el Centro de Experimentación Audiovisual y el Laboratorio de TeatroDanza del Instituto di Tella, creado y dirigido por ella entre 1967 y 1970 (ZIMMERMANN, 2007: 100-101).

La estrecha colaboración de Adolfo Reisin con el TLI se interrumpe en 1966 cuando se traslada a París por un periodo de aproximadamente un año. Disponemos de poca información acerca de esta etapa: en una nota del periódico Aurora que recogía el paso del "máximo compositor argentino de música para el teatro" por Israel, se afirmaba que había sido invitado por la Radio Televisión Francesa para perfeccionar estudios con Maurice Le Roux ${ }^{16}$. Al margen de este dato, en los currículos de Reisin publicados en varios folletos y programas de sus talleres se cita que fue becario del Groupe de Recherches Musicales, si bien en el exhaustivo trabajo de Évelyne Gayou sobre el grupo fundado por Pierre Schaeffer en 1958 no se menciona el nombre de Reisin, pero sí el de otro compositor becado por el GRM con el que nuestro autor mantendría una fructífera relación: Robert Cohen-Solal (GAYOU, 2007: 145-146). Algunos de los nombres que presumiblemente conocería Reisin en esta etapa - citados por él mismo en la entrevista que le realizamos- fueron François Bayle, Ivo Malec, Bernard Parmegiani, Guy Reibel o Luc Ferrari, todos ellos con obras electroacústicas programadas por el GRM en la temporada de 1966 (GAYOU, 2007: 125-126).

Ese mismo año, Pierre Schaeffer publicaría su influyente Traité des objets musicaux (Éditions du Seuil, 1966). Si bien es cierto que Reisin no posee en su catálogo obras electroacústicas

\footnotetext{
14 VALLES, Susana. Adolfo Reisin, Los Independientes, y un arte de "confluencias". Hoy en la cultura, Buenos Aires, n. 15, s/p, jul. 1964.

15 Programa de mano de la conferencia celebrada en el Teatro San Martín el 23 de agosto de 1965.

16 M. D. Adolfo Reisin en Israel. El máximo compositor argentino de “música para el teatro" llegó a Israel de paso para Francia. Aurora, s/p, 31 mar. 1966.
} 
El Músico Argentino Adolfo Reisin y las Estéticas de la Improvisación Colectiva Daniel Moro Vallina

o relacionables con las técnicas de la música concreta, Schaeffer y su teorización del objeto sonoro se convertirían en un pilar importante de su estética. En dos entrevistas publicadas en 1984, Reisin resumía la evolución musical del siglo XX en tres "rupturas" representadas respectivamente por el dodecafonismo de Schoenberg, la música concreta y, finalmente, por el advenimiento de la libre improvisación ${ }^{17}$. Por otro lado, la noción del objeto sonoro-musical -entendido este como el producto perecedero de la improvisación por oposición al objeto tradicional duradero, la partitura ${ }^{18}$ - sería uno de los puntos a trabajar en sus talleres de improvisación colectiva "De la experimentación a la creación", programados en cuatro partes o tiempos:

\section{Tiempo primero}

El Cuerpo en acción, instrumento esencial para la expresión musical, teatral y danzada. Sistemas interactivos de "tensiónrelajación". El movimiento y la gestualidad. El "discurso vocal". Alfabetos "onomatopéyicos".

\section{Tiempo segundo}

Interacción "corporal-vocal-instrumental": el Contrapunto fundamental. Origen del "Objeto Sonoro"; análisis de texturas, densidades, alturas, aleaciones. La Rítmica y la Tímbrica en los objetos sonoros.

\section{Tiempo tercero}

Interacciones entre los objetos sonoros: el "despertar" de la "gramática musical". Articulaciones, duraciones, pausas, intensidades, contrapuntos y movimientos: el "despertar" de una gramática musical danzada y teatral.

\footnotetext{
17 BOUILLY, Víctor. Adolfo Reisin: “Crear y enseñar van juntos”. Tiempo argentino, Buenos Aires, p. 8, 31 may. 1984. 18 CAMPS, Pompeyo. Adolfo Reisin: argentino, compositor y pedagogo. La música, en libertad. Clarín, Buenos Aires, p. 4 , 16 jun. 1984.
} 
El Músico Argentino Adolfo Reisin y las Estéticas de la Improvisación Colectiva Daniel Moro Vallina

\section{Tiempo cuarto}

Teoría y práctica del Solfeo Corpo-Gestual. El "Solfeador" en la Creación Colectiva e improvisación grupal. Contenidos y gramáticas en la construcción del discurso. El intérprete y el personaje: el "despertar" del Teatro-Musical-Danzado ${ }^{19}$.

\section{Hacia la Improvisación Colectiva y el Solfeo Corporal- Gestual}

En 1967 Adolfo Reisin retorna a la Argentina para visitar el Instituto di Tella, por aquel entonces dividido en tres organismos: el Centro de Artes Visuales, el Centro Latinoamericano de Altos Estudios Musicales — dirigido por Alberto Ginastera- y el Centro de Experimentación Audiovisual. En la tesis de María Fernanda Pinta sobre los espectáculos y medios audiovisuales del Di Tella (2010) se recoge el programa de Danza Ya (noviembre de 1967), creada por Susana Zimmermann y bajo la dirección musical de Reisin. Se trataba de una "experiencia de creación grupal" que reunía a bailarines, actores, músicos, poetas y artistas plásticos con el propósito de "realizar una comunicación total a partir de determinados estímulos que funcionan como marcos referenciales" (PINTA, 2010: 371). Algunos de esos estímulos, según se explicaba en una nota de prensa sobre el espectáculo, eran poemas de César Vallejo, fragmentos de Rayuela de Cortázar o las noticias de un diario vespertino, a partir de las cuales se invitaba al público a "psicodanzar" este material20.

Con esta obra y las experiencias vividas en el Di Tella se inicia una nueva etapa creativa que desembocará en la práctica de la improvisación. Aunque Reisin no fue becario del Instituto, en 1967 asistió al seminario impartido por Luigi Nono sobre sus

\footnotetext{
19 Este programa se repite en varios talleres celebrados desde la década de 1980 en Argentina, Brasil y España. Citamos uno de los últimos, sin fecha en el folleto, pero posterior a 2006 por figurar en el documento el último domicilio que ocupó Reisin hasta su fallecimiento (Gijón, Asturias).

20 J. P. Sociología, danza y diapositivas en una sola función. La prensa, Buenos Aires, p. 29, 1 oct. 1967.
} 
El Músico Argentino Adolfo Reisin y las Estéticas de la Improvisación Colectiva Daniel Moro Vallina

experiencias en el Studio di Fonologia de la RAl, que incluía la audición de obras electroacústicas como Ricorda cosa ti hanno fatto a Auschwitz, La Fabbrica Illuminata o A floresta é jovem e cheja de vida (NOVOA, 2011: 26). El año anterior había visitado el Di Tella el compositor griego lannis Xenakis con una conferencia sobre música estocástica. Ambos nombres también van a influir en la evolución estética de Reisin desde el punto de vista de la experimentación con la voz. En el caso de Xenakis, nuestro músico se encargó de dirigir obras corales suyas como Nuits (1967-68), y en su domicilio se conservan otras partituras que presumiblemente habría interpretado en algún momento, como À Hélène (1978) y Pour la paix (1981), para coro solo. Como veremos posteriormente, los ejercicios de improvisación vocal ideados por Reisin muestran un paralelismo con los recursos texturales de Xenakis, en forma de fonemas y onomatopeyas mantenidos en glissandi entre las diferentes voces. Respecto a Luigi Nono, el propio Reisin recordaba que en su seminario - titulado "Música y palabra: Experiencias de composición en un Laboratorio de Música Electrónica" (VÁZQUEZ, 2011: 85)- explicaba a los asistentes algunas técnicas de disección silábica de un texto y la voluntad de extraer el contenido expresivo por encima del significante vocal ${ }^{21}$. Estos recuerdos se relacionan con la experimentación de Nono en el medio teatral y la idea de una "dramaturgia puramente acústica" (RIZZARDI, 1999: 49), que lleva al compositor a querer dotar al material electroacústico del máximo poder de representación propio de la palabra. La huella de Nono también se observa en una propuesta posterior de Reisin estrenada en el Festival Experimenta 2000 y titulada Contrapunto Bestiale a la Vida, una paráfrasis de la obra Contrappunto dialettico alla mente (1968) subtitulada "composición de música vocalinstrumental de creación colectiva en tiempo real" (Figura 2):

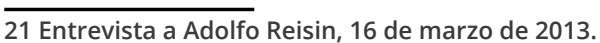


El Músico Argentino Adolfo Reisin y las Estéticas de la Improvisación Colectiva Daniel Moro Vallina

Figura 2 - Textos de la obra Contrapunto Bestiale a la Vida de Adolfo Reisin.

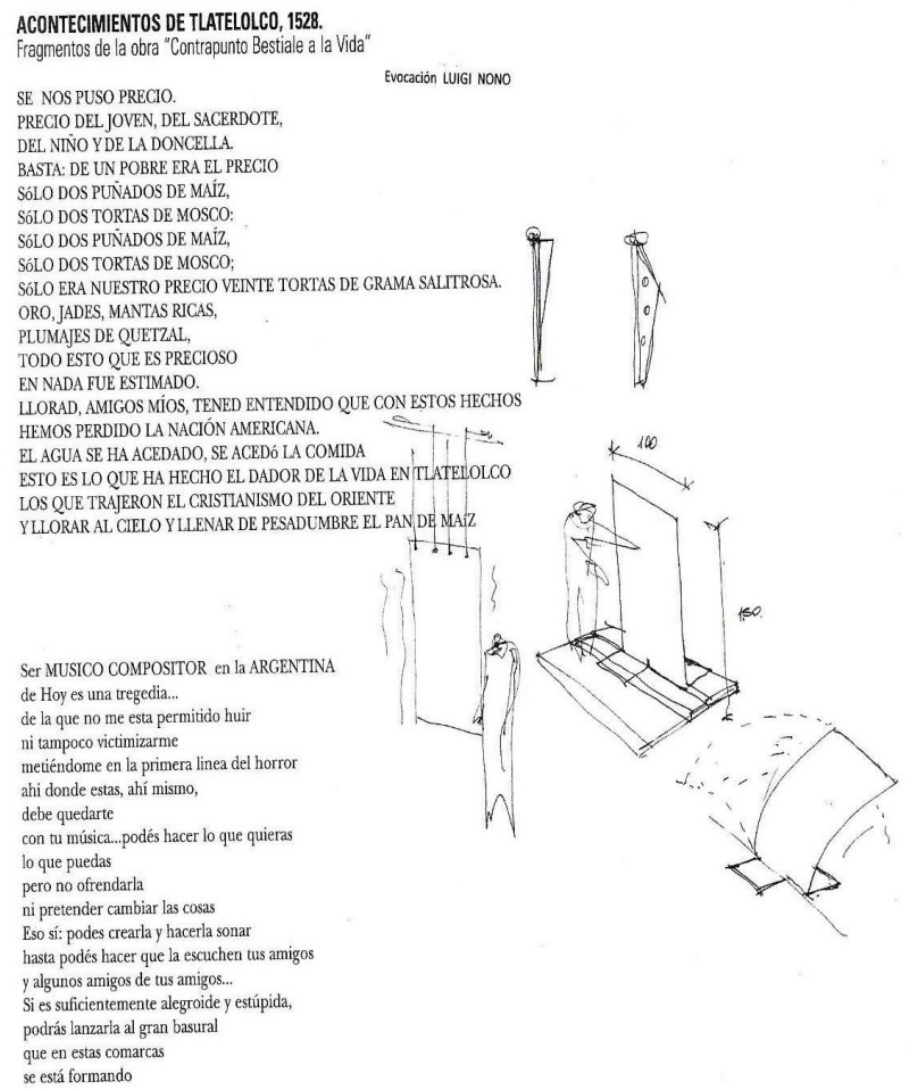

Fuente: Programa del Festival Experimenta 2000 (Buenos Aires, 2-11 de octubre de 2000), p. 60. Programa de mano cedido por el músico al autor.

Entrando ya en la improvisación, la aproximación de Reisin se sitúa en un contexto de especial florecimiento de esta práctica. Desde finales de la década de 1960, el movimiento de la Free European Improvisation vive su momento álgido a través de grupos como el Instant Composer's Pool (Países Bajos), el Spontaneous Music Ensemble (Reino Unido), la Globe Unity Orchestra (Alemania), Musica Elettronica Viva o el Gruppo di Improvvisazione Nuova Consonanza (Italia). En gran medida, lo que caracterizó a estos y otros colectivos fue su interés por superar no solo el binomio compositor-intérprete sino también eliminar cualquier tipo de jerarquía musical institucionalizada, lograr una interacción efectiva entre los músicos y emancipar el sonido idiomático del instrumento (IRETA, 2019: 6). Otro rasgo común fue su actitud 
El Músico Argentino Adolfo Reisin y las Estéticas de la Improvisación Colectiva Daniel Moro Vallina

contestataria y crítica hacia la cultura dominante del sistema capitalista, proponiendo un modelo de creación colectiva más igualitario y democrático.

La libre improvisación también se oponía a las experiencias de la música aleatoria iniciadas en la década anterior. Como señala Wade Matthews, el hecho de que algunos colectivos como el Instant Composer's Pool prefiriesen el término composición instantánea al de improvisación permitía evitar la falsa antítesis entre ambos conceptos como prácticas distintas (MATTHEWS, 2002: 16). Dos de los compositores más representativos de la aleatoriedad europea, Luciano Berio y Pierre Boulez, rechazaron la improvisación bajo el argumento de su falta de "unanimidad verdadera de discurso" o el hecho de soslayar "las cuestiones fundamentales de la invención, a saber, la relación entre estructura y materia" (MATTHEWS, 2002: $26,32)$. Ambas opiniones se enmarcan en la identificación de la creación musical con la escritura, de modo que la improvisación que se exigía durante un periodo concreto de tiempo en las obras aleatorias era adoptada de manera idiomática, como un recurso compositivo más. Se produce así una contradicción entre la supuesta libertad concedida a los intérpretes y la prescripción de unas normas individuales para llevarla a cabo. Bernardino Fantini explica otro de los equívocos en torno al binomio composiciónimprovisación: distinguir la primera como una actividad racional y la segunda como expresión directa y espontánea de la vivencia emocional del músico. En ambos casos surgen esquemas, normas o estilos de pensamiento que organizan el discurso, de tal manera que "la diferencia entre composición e improvisación parece ser solo el carácter directo o indirecto del producto final y su duración en el tiempo" (FANTINI, 2014: 47)22.

Un tercer prejuicio concibe la improvisación como producto del azar o del caos. Alessandro Bertinetto señala que, lejos de ser creatio ex nihilo, la improvisación se caracteriza por "la coincidencia entre ideación y creación, entre invención y acción, lo que [Luigi] Pareyson llama formatividad" (BERTINETTO, 2014: 17). Dicho

22 Cita traducida a partir del original: “La differenza fra composizione e improvvisazione sembra essere solo il carattere diretto o indiretto del prodotto finale e la sua durata nel tempo". 
El Músico Argentino Adolfo Reisin y las Estéticas de la Improvisación Colectiva Daniel Moro Vallina

principio, tomado del filósofo de Turín, se refiere a la creación de normas no instituidas previamente sino surgidas en el curso de la performance, capaces de combinarse y modificarse para crear otras nuevas: una "formatividad recursiva". La improvisación, incluso la más libre y experimental basada en la exploración acústica del sonido en sí mismo por oposición a la idiomática del free jazz (IRETA, 2019: 2), no involucra "una música sin forma, sino que es una música constructora de formas, en el mismo momento en que viene realizada como producto individual o colectivo" (FANTINI, 2014: 51)23. Por otro lado, esta normatividad en proceso implica un entrenamiento y preparación a veces más exigentes que los de la composición escrita; para Paul F. Berliner, cuando un improvisador introduce un nuevo recurso en su bagaje musical, inmediatamente tendrá que resguardarse de su uso rutinario o poco inspirado (BERLINER, 2002: 92).

Varias de estas ideas subyacen a la manera en la que Reisin se inició en la improvisación. Como él mismo nos explicaba, su experiencia estuvo condicionada por la dirección de obras que incluían secciones no determinadas libradas al quehacer de los intérpretes, pero nacidas de una sola mente creativa. Ello generaba una contradicción que desembocaba en un clima de cierta incomodidad entre los músicos:

Derepente, llega un compás donde dice "a partir de aquí 2 minutos 30 segundos de improvisación". Y nada más [...] El compositor no daba explicaciones [...] Me acuerdo de esas obras que yo tuve que dirigir. Al principio yo paraba, me quedaba inmóvil y viendo mi cronómetro mirando y escuchando eso. Nadie sabía lo que podía pasar. Y que lo más importante para los músicos era una cosa absolutamente impensada. Había una situación un poco humorística y un poco intimidatoria. No sabíamos lo que hacer o cómo hacerlo [...].

23 Cita traducida a partir del original: “L'improvvisazione non comporta affatto della 'musica senza forma', ma è una 'musica costruttice di forme', nel momento stesso in cui viene realizzata come prodotto, individuale o collettivo". 
El Músico Argentino Adolfo Reisin y las Estéticas de la Improvisación Colectiva Daniel Moro Vallina

Las primeras veces el director se quedaba inmóvil mirando el cronómetro, cosa que me hacía distraerme y no escuchar lo que estaban haciendo los músicos [...] Había dos o tres momentos de improvisación en una obra totalmente escrita. Después, cuando hacíamos el análisis con el compositor, algunos de los muchachos empezaron a decir "es divertido, yo toqué cualquier cosa, a mí no me dijo nada". Teníamos que repetir la obra en otro concierto, y le decíamos al compositor: "¿podemos improvisar un poquito más?" Una segunda vez, y los músicos cada vez queríamos más. En mi caso como director, a medida que íbamos repitiendo esa experiencia, yo no aguantaba estando inmóvil, y cada vez me vinculaba más a lo que estaba ocurriendo en la improvisación [...] con algunos gestos, primero más disimulados, y me fui abriendo en una comunicación con el grupo más gestáltica. Finalmente, esta comunicación gestáltica los músicos la empezaron a observar y decidimos hacer solo improvisación ${ }^{24}$.

Salvando las distancias, el paso de la experiencia aleatoria a la improvisación libre por parte de Reisin fue similar al de otro protagonista de la época: Franco Evangelisti y su Gruppo di Improvvisazione Nuova Consonanza. Reisin citaba concretamente el GINC entre otras manifestaciones propias de aquella tercera "ruptura" de la que hablaba, y que habían influido en la educación musical ${ }^{25}$. Es significativo que, en 1962, Evangelisti renunciase a la composición escrita y fundara el GINC en Roma poco después, activo entre 1965 y 1969. Igualmente, existen coincidencias respecto a la dimensión ideológica que ambos concedían a la improvisación como alternativa a la mercantilización de la música contemporánea. Para Evangelisti, Nuova Consonanza constituía un ejemplo único en el mundo musical, "libre e intacto de presiones del mundo capitalista, sin que por esto sea anónima o anárquica como siempre se ha intentado que parezca" (1978, citado en TORTORA,

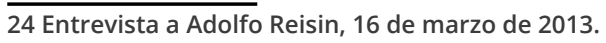

25 Documento mecanografiado de 8 páginas, sin título, fechado en Río de Janeiro, junio de 1981, p. 6. Otras experiencias citadas por Reisin eran el piano preparado de John Cage, la música concreta de Pierre Schaeffer y Pierre Henry, el tablero UPIC de lannis Xenakis o el teatro musical de Mauricio Kagel. 
El Músico Argentino Adolfo Reisin y las Estéticas de la Improvisación Colectiva Daniel Moro Vallina

1990: 36$)^{26}$. De forma similar, Reisin comprendía que la ruptura simbolizada por el advenimiento de la libre improvisación se había producido "en planos transpolíticos, tanto en el capitalismo como en el socialismo, y en vez de profundizar en sofisticaciones tecnológicas, se regresa a prácticas musicales primitivas, al margen del esquema producción-consumo"27.

Daniela Tortora ha estudiado la trayectoria del GINC en Italia. Una de las conclusiones que extrae de la actividad del grupo era la novedad de sus objetivos: confrontar la tradición improvisatoria basada en códigos tradicionales —eljazz, por ejemplo_yla búsqueda de una suerte de "lenguaje originario" más allá de la tradición escrita occidental (TORTORA, 1990). A través de la experimentación tímbrica y la ausencia de una planificación formal, el GINC practicó una economía de materiales que buscaba retornar a la esencialidad del dato sonoro, reduciendo su dimensión semántica. También fue característica su tendencia hacia las prescripciones "negativas" y la exploración continua de nuevos usos instrumentales como verdadera forma de vanguardia. Se trata del principio de "acciónreacción", por el cual los improvisadores debían responder ante un estímulo sonoro libremente pero cumpliendo tres reglas: no repetirlo o imitarlo, evitar usar los mismos patrones rítmicos y eludir aquellos recursos ya aprendidos o heredados de la tradición (BERTOLANI, 2019). También la práctica de Reisin, a pesar del aparente laissez faire que concede a los músicos, está regulada por principios de escucha y reacción recíprocos que contradicen la visión popular de la libre improvisación como una actividad puramente espontánea o azarosa.

Contamos con dos testimonios acerca de cómo se desarrollaban los talleres de creación-improvisación colectiva de Adolfo Reisin. El primero son las impresiones de un crítico italiano tras asistir a uno de los Laboratori di sperimentazione musicale que organizó en Roma en la década de 1970 (véase Figura 3). En el texto se explicaba el

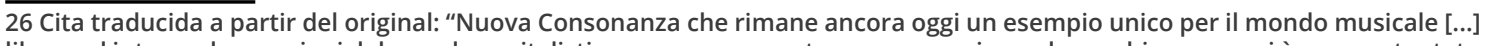
libera ed integra da pressioni del mondo capitalistico, senza per questo essere anonima ed anarchica, come si è sempre tentato di farla apparire".

27 CAMPS, Pompeyo. Adolfo Reisin: argentino, compositor y pedagogo. La música, en libertad. Clarín, Buenos Aires, p. 4, 16 jun. 1984. 
El Músico Argentino Adolfo Reisin y las Estéticas de la Improvisación Colectiva Daniel Moro Vallina

método de Reisin como una vía para descubrir la "autoconsciencia musical" de cada persona:

Un hombre, el profesor Reisin, en el centro de un semicírculo de personas, dirige con los mismos métodos de un director de orquesta respiraciones, vocalizaciones, gorjeos y notas altas de algunos, mientras sugiere gestos y posiciones a otros, que se mueven en busca de una relación con su cuerpo, a menudo rodando por el suelo [...].

El efecto es, al inicio (para el profano), un aparente caos que recuerda al Marat-Sade, pero con el tiempo la situación revela temas musicales precisos y un alto valor de comunicación y participación entre quienes están comprometidos en el taller. No hay nada "espontáneo" ni casual; al contrario, todo se desarrolla bajo la influencia de una búsqueda racional y consciente de la capacidad expresiva, que Reisin considera "atrofiada" por los arquetipos culturales dominantes ${ }^{28}$.

Figura 3 - Cartel de uno de los talleres desarrollados por Adolfo Reisin en Roma.

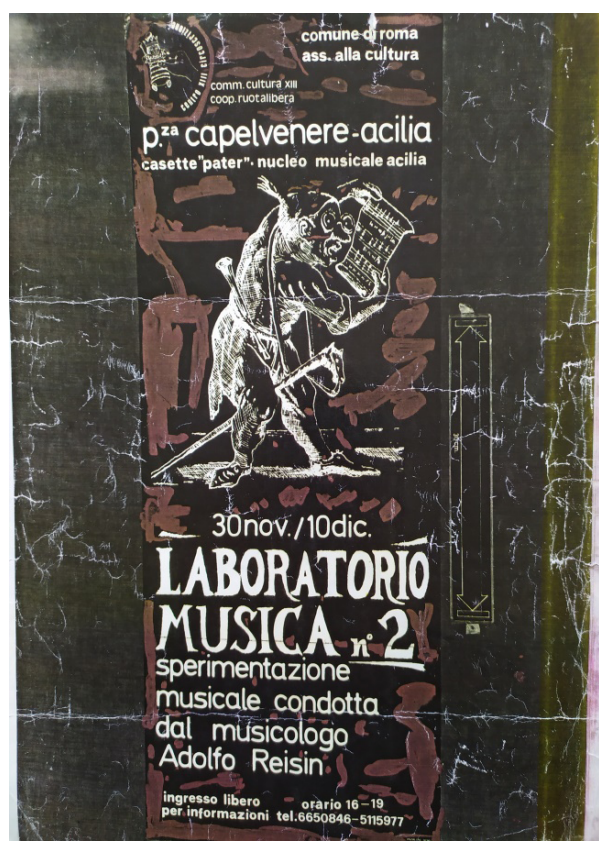

Fuente: Archivo personal de Adolfo Reisin (Gijón, España).

28 BENIGNI, Glauco. L'autocoscienza musicale. La Repubblica, Roma, s/p, 2 ago. 1977. Traducción nuestra a partir del original en italiano. 
El Músico Argentino Adolfo Reisin y las Estéticas de la Improvisación Colectiva Daniel Moro Vallina

El segundo testimonio corresponde a la videograbación de otro taller celebrado el 5 de abril de 1997 en el Conservatorio Nacional de Música de Buenos Aires. El vídeo recoge cuatro improvisaciones: la primera a capella y las siguientes para voz e instrumentos diversos (véase Figura 4) ${ }^{29}$. Describimos la primera improvisación vocal —de unos 17 minutos de duración-, que en conjunto puede verse como una serie de momentos articulados por procesos de estatismo-dinamismo y tensión-relajación, en función de cómo responde el grupo a los gestos del solfeador. Este último (Reisin) da las entradas y salidas, pero también se adapta al proceso reaccionando gestualmente a las iniciativas sonoras de los integrantes. Para tratar de entender mejor su propuesta, combinamos la descripción de las acciones con las indicaciones literales del solfeador:

1. Primera parte explicativa: "no hay códigos entre nosotros, no hay pautas, no estamos haciendo improvisación en jazz".

2. Minuto 03:48: respiración-susurros largos (Reisin) modelada por gestos manuales ("esta es una frase musical: intervinieron las alturas, las intensidades y la duración"). Este primer material se interrumpe con un golpe de glotis ("a due voci: soplido y la cuerda que empieza a intervenir"). El tercer elemento son vocalizaciones ("toda la exploración de fonemas, otro alfabeto para-verbal basado en el contrapunto y el contraste"). Un ejemplo simple de dicho contraste: susurro largo e interrupción con vocales cortas y agudas ("sonidos blandos y duros", respectivamente).

3. Minuto 07:35: inicio de la improvisación ("una respiración y una emisión. Después vamos fraccionando. Todos juntos o por turnos"). Susurros largos en diversas fases temporales (respiración), combinados con vocalizaciones largas y cortas (emisión). La intensidad y la duración varían según el

29 Laboratorio "De la experimentación a la creación”. Conservatorio Nacional de Música, prof. Reisin, abril de 1997. Cinta VHS de 1:32:58 de duración. Archivo personal de Adolfo Reisin. 
El Músico Argentino Adolfo Reisin y las Estéticas de la Improvisación Colectiva Daniel Moro Vallina

solfeador se aproxima a los integrantes o señala a alguno en particular, abriendo y alzando los brazos.

4. Minuto 11:10: sonidos onomatopéyicos, chasquidos con la lengua, sílabas en parlato. Emisiones sobre vocales a distintas alturas, uniéndose al material anterior. Sonidos cada vez más cortos y agudos en accelerando.

5. Minuto 12:20: primer clímax de intensidad y altura. Descenso progresivo coincidiendo con los brazos en alto del solfeador y las palmas vueltas hacia el grupo.

6. Minuto 12:38: palabras inventadas emitidas por el solfeador, a las que el grupo responde con otras. Una de las integrantes toma la iniciativa entonando un pasaje. El solfeador reacciona y dinamiza al resto del grupo. Crescendo y accelerando.

7. Minuto 13:47: emisiones rápidas en parlato sobre las sílabas "mi-me". Vocalizaciones largas sobre las vocales "a-e". El solfeador dirige con diferentes gestos (dedos en la boca: sílabas en parlato; brazos y manos extendidos: vocales prolongadas).

8. Minuto 16:20: material contrastante (chasquidos con la lengua, sílabas "pi-ti" cortas en parlato y crescendo). Accelerando y ascenso progresivo de la altura.

9. Minuto 17:15: segundo clímax de 20 segundos, gritos prolongados coincidiendo con los brazos en alto del solfeador. Caída controlada ("la misma cosa a pianissimo").

10. Minuto 18:00: nuevo material, imitaciones onomatopéyicas. Sonidos graves en piano. Silencio súbito de 5 segundos.

11. Minuto 19:05: nuevo solo vocal, sonidos crepitantes en pianissimo y crescendo.

12. Minuto 19:58: introducción de un nuevo tipo de emisión, golpe de glotis grave y corto que se une al resto del material (vocalizaciones, silbidos y susurros rápidos). 
El Músico Argentino Adolfo Reisin y las Estéticas de la Improvisación Colectiva Daniel Moro Vallina

13. Minuto 20:40: la acción sonora se homogeneiza en todo el grupo: vocales entonadas y mantenidas en líneas a diferentes alturas en piano. Los gestos del solfeador describen círculos que hacen rotar el flujo sonoro. Señala a algunos miembros para variar la altura ("medio tono"). Intensidad estática ("flotad, escuchad").

14. Minuto 23:02: un integrante entona las sílabas "a-me" en un intervalo ascendente de $5^{\text {a }}$. El grupo responde con fragmentos de escalas descendentes que completan el intervalo. Diminuendo progresivo. Se vuelve a los susurros.

15. Minuto 23:49: únicamente susurros dirigidos por la gesticulación vocal en silencio del solfeador. Silencio final hasta 24:18.

Figura 4 - Videograbación de un taller celebrado en el Conservatorio Nacional de Música de Buenos Aires (1997).

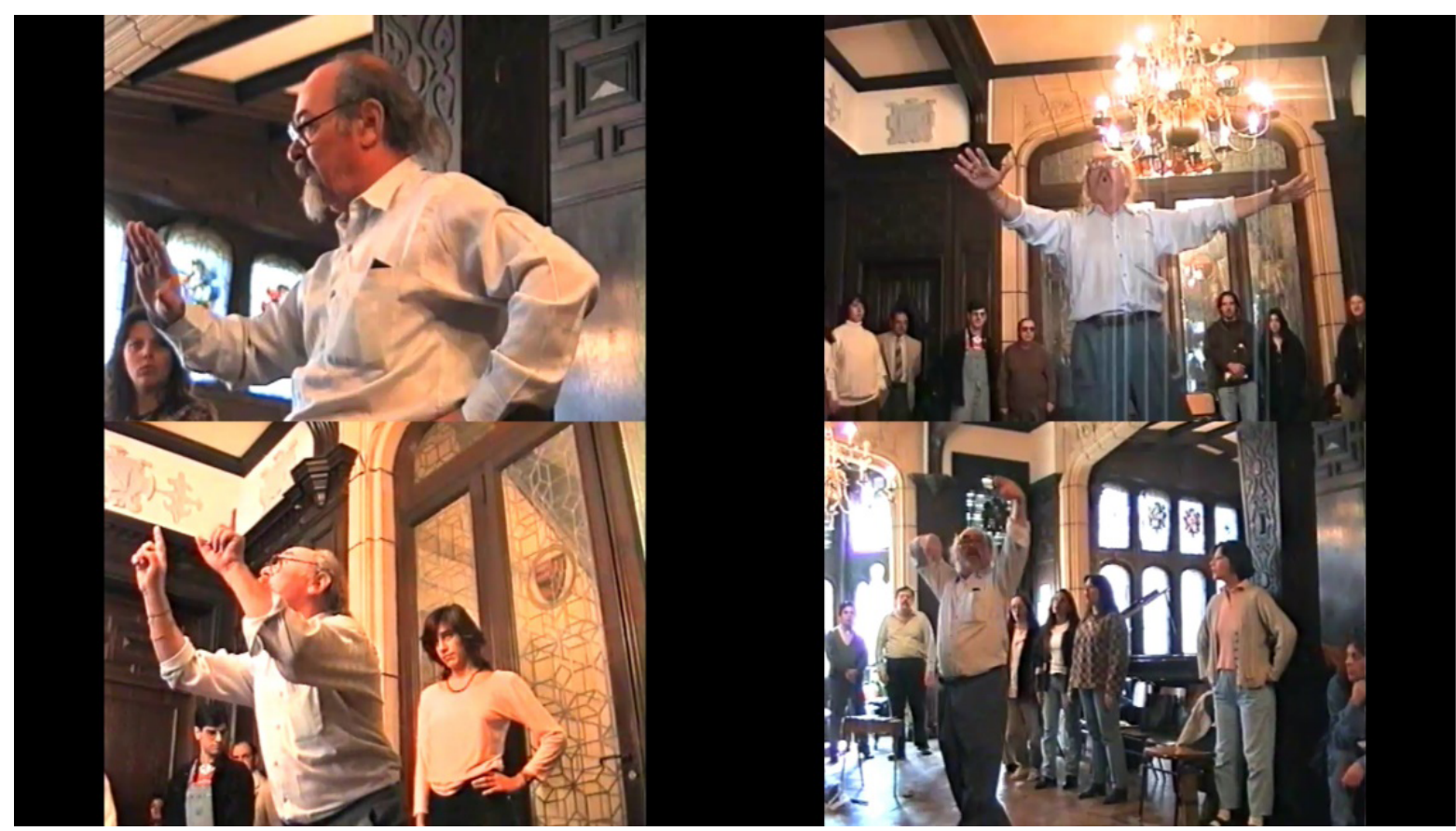

Fuente: Archivo personal de Adolfo Reisin (Gijón, España). Fotomontaje realizado por el autor a partir de la grabación en VHS. 
El Músico Argentino Adolfo Reisin y las Estéticas de la Improvisación Colectiva Daniel Moro Vallina

\section{La Vertiente Pedagógica de la Libre Improvisación}

Además de como fenómeno artístico, la improvisación ha sido estudiada desde el punto de vista psicológico y cognitivo, en relación con los modelos comunicativos de la primera infancia. Basándose en las investigaciones de Jean Piaget, Daniel Stern o Maya Gratier, Michel Imberty (2014) señala por ejemplo cómo desde el nacimiento los niños se comunican con la madre no imitando sus gestos y sonidos, sino llevando a cabo un juego de variaciones sobre un modelo común a ambos que comporta una gran parte de improvisación. En este proceso de intercambio en un mismo "timing expresivo" (IMBERTY, 2014: 7) la voz juega un rol fundamental: antes de aprender a hablar, el niño percibe el sentido de la palabra mediante la línea melódico-rítmica, la dinámica, la acentuación o el tempo, y el uso que hace de esta voz para expresarse está más cerca de la música que del lenguaje propiamente dicho. Imberty considera que el grado de indeterminación y anticipación que conlleva toda improvisación es, en última instancia, la fuente de la tensión y la emoción musicales, al punto de ver esta práctica como la "condición primaria de la comunicación intersubjetiva y de la musicalidad" (IMBERTY, 2014: 8) 30 .

El tipo de intersubjetividad que se da en la improvisación también ha sido explorada por algunas corrientes de la musicoterapia, como el modelo de orientación analítica de Mary Priestley (en el que el paciente improvisa su espectro emocional a partir de un estímulo dado) o la terapia de libre improvisación de Juliette Alvin (llamada así porque el terapeuta no impone normas a priori y el cliente se deja llevar hasta encontrar su propia manera de ordenar los sonidos). En los casos de trastornos del espectro autista, Carl Bergstrom-Nielsen muestra cómo la improvisación libre vocal ayuda al paciente a desarrollar habilidades expresivas y comunicativas utilizando sus propios sonidos vocálicos y guiando su variación controlada (BERGSTROM-NIELSEN, 2003). Frente al

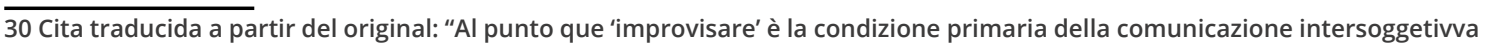
e della musicalità". 
El Músico Argentino Adolfo Reisin y las Estéticas de la Improvisación Colectiva Daniel Moro Vallina

desarrollo lineal de la improvisación artística profesional, el uso que se hace de ella en musicoterapia puede ser definido como circular en el sentido de que se establece un feedback continuo entre terapeuta (quien "interpreta" al paciente anticipando o respondiendo a sus acciones sonoras)y paciente (que representa un "tema vivo" a explorar y desarrollar por el terapeuta) (MANAROLO, 2014: 72).

Esta vertiente funcional de la improvisación caracteriza el trabajo que Adolfo Reisin desarrolló en varias guarderías de París entre 1977 y 1984, como parte de un programa organizado por el Centro de Asistencia Educativa e Investigaciones (AER) del Fondo de Intervención Cultural de Francia. Su propuesta viene recogida en una publicación colectiva sobre experiencias educativas innovadoras con la primera infancia en París (CARON y PÉTIGNY, 1995). En esencia, consistió en dirigir talleres de improvisación orientados tanto a niños como a adultos, bajo el lema de hacer música a través del juego y con un marcado espíritu de trabajo cooperativo, ya que daba la posibilidad a los participantes de convertirse en formadores al cabo de un tiempo. El proceso comprendió una primera fase experimental en la que el personal de guarderías vecinas asistía a los seminarios de improvisación de Reisin para explorar nuevas relaciones entre ellos y con los niños. Una vez finalizada esta etapa, en 1981 el ayuntamiento de París creó puestos de puericultoras coordinadoras que diseñaron junto a Reisin un proyecto de formación continua para otras guarderías, generando así nuevas redes de difusión. Los talleres se celebraban semanalmente y en ellos coincidían todos los trabajadores al margen de su estatus: directoras, educadoras, auxiliares y agentes de servicio, procedentes de diversos establecimientos (CARON y PÉTIGNY, 1995: 142).

Un aspecto central de la pedagogía de Reisin fue focalizar la improvisación como una forma de expresión no verbal. Siguiendo a Caron y Pétigny (1995), lo que se hacía hasta ese momento en las guarderías parisinas era cantar canciones infantiles o escuchar discos de música clásica. Por el contrario, Reisin proponía un 
El Músico Argentino Adolfo Reisin y las Estéticas de la Improvisación Colectiva Daniel Moro Vallina

retorno a la expresión primitiva de la música como medio de hacerla accesible a todo el mundo y lograr un lenguaje común: "No enseñamos solfeo ni técnicas instrumentales. Todo comienza en la producción salvaje de la música. En la anarquía y el caos que presiden este proceso, se encuentra la ocasión a la vez de descubrirse unos a otros y de conocerse mejor a sí mismos" ${ }^{\prime \prime 1}$. Esta vía conectaba dos extremos aparentemente opuestos: la forma natural del niño de comunicarse sonora y gestualmente sin emplear códigos estandarizados y la ampliación del concepto sonoro propia de la música contemporánea. Robert Cohen-Solal, músico con el que Reisin colaboró activamente en los talleres de improvisación y cofundó en 1980 la Asociación para el Desarrollo de la Música Contemporánea (ADMC), lo explicaba así en una entrevista realizada a ambos:

Es el modelo de "lo no-verbal" el que se aplica. Es el hecho de partir del postulado: "no va a emplearse el lenguaje verbal" lo que lo cambia todo. Entre adultos, entre músicos, entre compositores, es una regla del juego a la que uno se consagra. Los niños nos muestran el ejemplo gracias a sus posibilidades de comunicar, de expresarse a través de lo que no es verbal, de las onomatopeyas, gritos, cantos aparentemente caóticos. Ellos nos indican lo que puede ser una construcción de la expresión musical. Es una idea que se encuentra en los dos extremos de la cadena, del lado de los niños y del lado de una corriente musical que es la de la música contemporánea ${ }^{32}$.

Cohen-Solal también indicaba que "el método es simple. En primer lugar, una gimnasia corporal que se apoya en la respiración. Es un método aplicable a cualquier individuo, y ahí radica su originalidad"33. Una fuente primaria muy útil para indagar en su sistema es la memoria elaborada por Suzanne Ledoublee

\footnotetext{
31 Rien que la liberté! Le Monde de l'Éducation. París, p. 85, 1983. Fotocopia de una entrevista a Adolfo Reisin conservada en su archivo personal. Traducción nuestra a partir del original en francés.

32 MATHIAS, Christine. Une pédagogie de la liberté. Fotocopia de un artículo sin referencia conservada en el archivo personal de Adolfo Reisin. Traducción nuestra a partir del original en francés. 33 Ibídem.
} 
El Músico Argentino Adolfo Reisin y las Estéticas de la Improvisación Colectiva Daniel Moro Vallina

y Denise Mededji, dos puericultoras de París integrantes del proyecto de formación de Reisin y que colaboraron en sus talleres entre noviembre de 1981 y junio de $1984^{34}$. Según explican en el documento, la técnica de improvisación de nuestro autor se fundamentaba en tres aspectos:

- La noción de los impulsos sonoros que nacen a partir de la acción corporal.

- El estudio de los gestos musicales considerados como la base del despertar de las estructuras del lenguaje musical.

- La noción de las articulaciones y modulaciones en la estructura de la gramática musical, y la ruptura en relación a la música tradicional ${ }^{35}$.

Otro fragmento de la memoria recoge la secuenciación del taller de expresión vocal-instrumental practicado en las guarderías con niños y adultos. La primera acción, titulada "El cuerpo como instrumento musical", comprendía ejercicios de respiración nasal y vocalizaciones sobre los fonemas "i", "tz" y "ou", emitidos en una espiración continua y luego dividida en impulsos rítmicos. En la segunda acción, "La voz", Reisin planteaba ejercicios de glissandi ascendentes colectivos (moto perpetuo) e individuales en "tonalidades móviles" (dentro de un intervalo de $3^{3}$ ). A partir de aquí, cada participante desarrollaba sus propias ideas sonoras en diálogo con el resto, guiados por el solfeador. Otro ejercicio consistía en la exploración tímbrica mediante el uso de vocales y sílabas para-verbales hasta llegar a la "disección sonora" de palabras u onomatopeyas (véase Figura 5). El resultado es similar a las texturas continuas características de las citadas obras de Xenakis, construidas sobre distintos fonemas mantenidos en cada voz:

34 LEDOUBLEE, Suzanne y MEDEDJI, Denise. La musique dans le secteur de la toute petite enfance. Memoria mecanografiada de 168 páginas, inédita y sin fecha.

35 Ibídem. La traducción es nuestra a partir del original en francés. 
El Músico Argentino Adolfo Reisin y las Estéticas de la Improvisación Colectiva Daniel Moro Vallina

Figura 5 - Memoria La musique dans le secteur de la toute petite enfance, s/f, pp. 43-44.

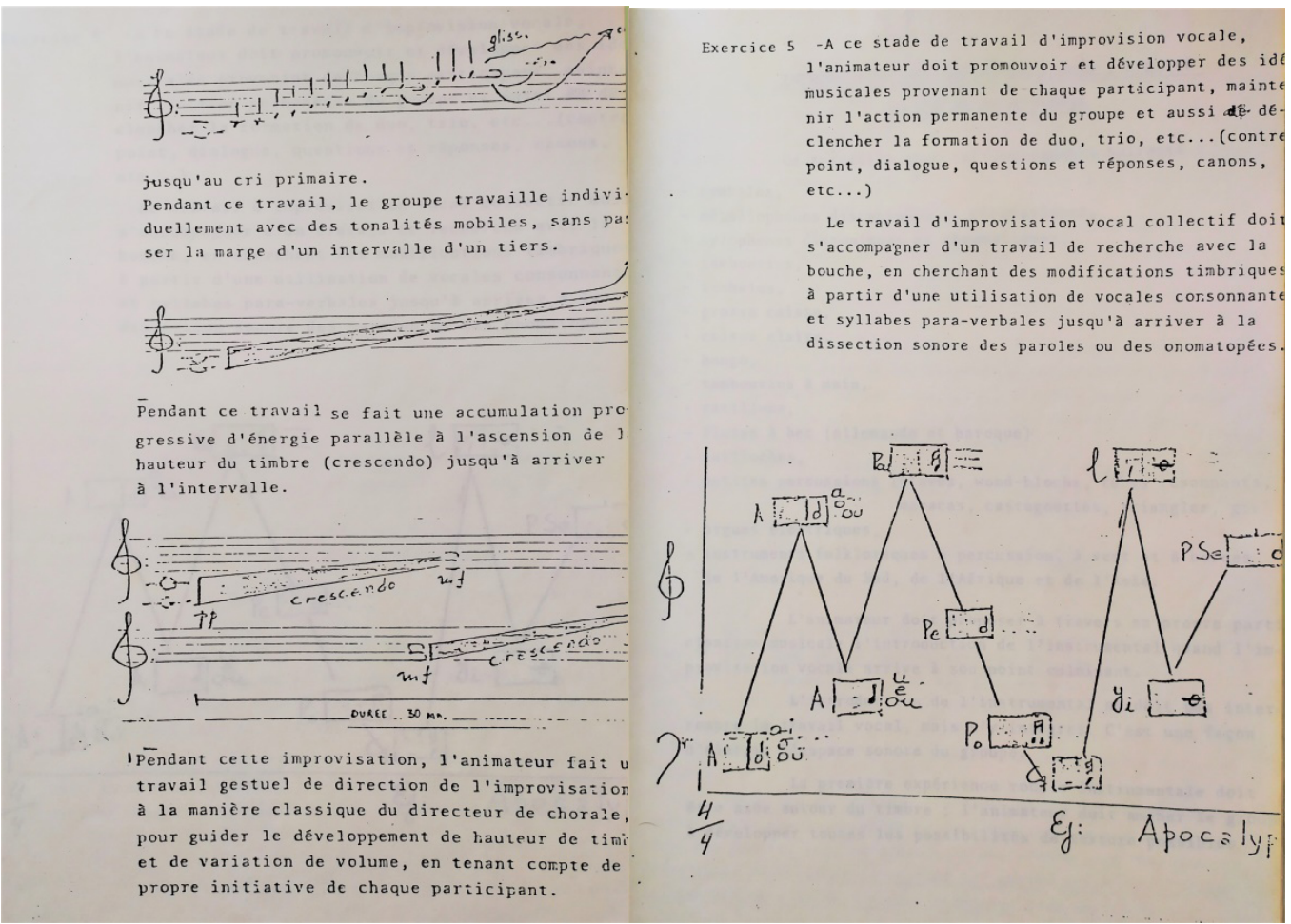

Fuente: Archivo personal de Adolfo Reisin (Gijón, España).

Una última cita de Reisin -extraída de un texto de autoanálisis seguramente destinado a uno de sus seminarios- profundiza en el rol del solfeador como intermediario entre la naturaleza subjetiva de los participantes y ciertas leyes de la expresión sonoro-musical:

Para precisar un poco más la idea del rol del Solfeador en su acción práctica, diremos que su función técnica consiste - al mismo tiempo que realiza su propia acción participante- en solfear [...] corporal y gestualmente, una música que no está escrita, y que en realidad, ni siquiera existe, mas que está en su etapa del nacimiento o despertar, generada por impulsos, mecanismos y energía localizados en el Cuerpo, instrumento básico y fundamental, que engendrará los Objetos Sonoros internos (la voz) y externos (los instrumentos) por él manipulados.

De esta manera, los objetos sonoros, en la etapa siguiente, comenzarán el proceso de relacionamiento, en tanto materia, en 
El Músico Argentino Adolfo Reisin y las Estéticas de la Improvisación Colectiva Daniel Moro Vallina

articulaciones y dinámicas que se irán desarrollando dentro de los parámetros clásicos de Tiempo (rítmico) y de Alturas (armónicostímbricos) generando texturas, condensaciones acústicas y contrapuntísticas que darán lugar más tarde a las primeras imágenes sonoras y combinaciones que podríamos llamar pre-gramaticales.

Es en ese momento que el Solfeador deberá echar mano a sus propios recursos perceptivos y lingüísticos para descubrir -y hacer descubrir - detrás de las formas y sus evoluciones en el tiempo y en el espacio, el contenido que comienza a asomar, a despertar en el interior de cada uno, para compatibilizarlo con los contenidos de los demás: son las funciones que permitirán al Solfeador estructurar el "medio caótico" del inicio y facilitar la integración del grupo en dichas funciones $[. . .]^{36}$.

\section{Conclusiones}

Lejos de constituir etapas autónomas dentro de su carrera, el trabajo de Adolfo Reisin para el teatro durante los años 60, su práctica de la libre improvisación en los 70 y la orientación pedagógicaqueleconfirió posteriormentesonaspectosgobernados por un mismo principio: explorar nuevas formas de comunicación artística que integrasen sonido, gesto y acción. El hecho de haberse formado como músico teatral marcaría su voluntad de vincular más estrechamente la música con la acción dramática y gestual, confluyendo ambas en un mismo producto. Poco después de su debut, el contacto con Susana Zimmermann y el mundo de la danza le permitirían desarrollar aún más esta dimensión interdisciplinar y concebir el cuerpo como instrumento musical, principio que está en la base de su teorización del solfeo corporal-gestual. Por otra parte, el gusto de Reisin por el teatro social de Brecht revela un perfil ideológico de izquierdas y comprometido con la libertad, ideales que también se manifestaron en su adopción de la improvisación como un medio más democrático respecto a los

36 Documento mecanografiado de 8 páginas, sin título, fechado en Río de Janeiro, junio de 1981, p. 7-8. 
El Músico Argentino Adolfo Reisin y las Estéticas de la Improvisación Colectiva Daniel Moro Vallina

roles institucionalizados del creador, intérprete y público propios de la composición escrita.

Las influencias de Pierre Schaeffer, Luigi Nono e lannis Xenakis - compositores a los que Reisin conoció personalmentepueden rastrearse en su estética. En el primer caso, la ruptura respecto a las cualidades referenciales del sonido y la exploración acústica de la música concreta se reflejan en el rechazo de Reisin por el solfeo y la teoría musical convencionales. Aunque en su práctica no empleó el medio electroacústico, el objeto sonoro de Schaeffer aparece mencionado como un punto a trabajar en sus talleres de improvisación, entendiéndolo como el producto de la libre exploración tímbrica por parte de los participantes, luego moldeada por las intervenciones del solfeador. En cuanto a Nono y Xenakis, su huella se revela en el uso que Reisin hace de fonemas, onomatopeyas u otros elementos paralingüísticos como forma de expresión dramática más allá del significante verbal, de manera similar a las obras electroacústicas de Nono o las corales de Xenakis. En el caso de este último, algunos detalles de los ejercicios de improvisación de Reisin —glissandi, grupos de fonemas móviles entre las voces- son similares a los recursos utilizados en Nuits o Pour la paix, por ejemplo.

La práctica improvisatoria de Reisin no se asemeja a los códigos estandarizados del jazz ni tampoco a la estructuración formal propia de la música aleatoria. Su ideal fue una improvisación libre y experimental nacida de un aparente caos que, a través de un proceso de creación colectiva, iba ordenándose según se desarrollaba. En este sentido, existe un paralelismo entre el modelo de Reisin y el de Franco Evangelisti y su Gruppo di Improvvisazione Nuova Consonanza. Sin embargo, estos últimos no dejaban de ser músicos profesionales que se reunían en privado para improvisar y concebían su trabajo con fines puramente artísticos o estéticos. Por el contrario, la visión que Reisin tenía de la improvisación fue mucho más amplia: hacer de ella un lenguaje musical accesible a todo el mundo, profesionales y amateurs, adultos y niños, a través de una técnica -el solfeo corporal-gestual- que explota ciertos 
El Músico Argentino Adolfo Reisin y las Estéticas de la Improvisación Colectiva Daniel Moro Vallina

principios universales de la expresión y la comunicación humanas. Este artículo pretende ser el punto de partida de ulteriores investigaciones que exploren nuevos aspectos del potencial artístico y pedagógico de la libre improvisación colectiva de Adolfo Reisin.

\section{Referencias}

BERGSTROM-NIELSEN, Carl. Musicoterapia e improvisación libre.

Tavira: Revista de ciencias de la educación, Cádiz, n. 19, pp. 223-230, 2003. Disponible en <https://rodin.uca.es/xmlui/handle/10498/7757>. Acceso el: 2 may. 2021.

BERLINER, Paul F. Las vicisitudes del solista. Doce Notas Preliminares. Improvisación, crear en el momento, Madrid, n. 10, pp. 91-108, 2002. BERTINETTO, Alessandro. Formatività ricorsiva e costruzione della normatività nell'improwvisazione. En: SBORDONI, Alessandro (Ed.). Improvvisazione oggi. Lucca: Libreria Musicale Italiana, 2014. pp. 15-28. BERTOLANI, Valentina. Improvisatory Exercises as Analytical Tool: The Group Dynamics of the Gruppo di Improvvisazione Nuova Consonanza. Music Theory Online, v. 25, n. 1, 2019. Disponible en <https://www. mtosmt.org/index.php>. Acceso el: 20 abr. 2021.

CARON, Danielle y PÉTIGNY, Alix de. Les réseaux « musique ». En: BRÉAUTÉ, Monique y RAYNA, Sylvie (Coords.). Jouer et connaître chez les tout-petits. Des pratiques éducatives nouvelles pour la petite enfance. Paris: Institut National de Recherche Pédagogique, 1995. pp. 141-147.

CORDA, María Cecilia. Las vanguardias políticas de los años 70: la experiencia del PRT ERP, desajuste y distanciamiento de la realidad. Tesis de posgrado. Facultad de Humanidades y Ciencias de la Educación de la Universidad Nacional de La Plata, 2006. 127 p. Disponible en <https://repositorio.flacsoandes.edu.ec/xmlui/ handle/10469/1112>. Acceso el: 26 mar. 2021. 
El Músico Argentino Adolfo Reisin y las Estéticas de la Improvisación Colectiva Daniel Moro Vallina

FANTINI, Bernardino. Ripensare l'improvvisazione. En: SBORDONI, Alessandro (Ed.). Improvvisazione oggi. Lucca: Libreria Musicale Italiana, 2014. pp. 43-56.

GAYOU, Évelyne. Le GRM Groupe de Recherches Musicales. Cinquante ans d'histoire. Francia: Librairie Arthème Fayard, 2007. 520 p.

IMBERTY, Michel. Sguardi dello psicologo sull'improvvisazione ed i suoi contesti nella musica del XX secolo. En: SBORDONI, Alessandro (Ed.). Improvvisazione oggi. Lucca: Libreria Musicale Italiana, 2014. pp. 3-14. IRETA, Iván Tadeo. La improvisación libre en solo: una aproximación fenomenológica y una proposición de análisis. Tesis de doctorado. Departamento de Arte y Musicología de la Universidad Autónoma de Barcelona, 2019. 398 p. Disponible en <https://ddd.uab.cat/ record/238496>. Acceso el: 2 may. 2021.

MANAROLO, Gerardo. L'improvvisazione sonoro/musicale come opportunità espressiva, comunicativa e relazionale. En: SBORDONI, Alessandro (Ed.). Improvvisazione oggi. Lucca: Libreria Musicale Italiana, 2014. pp. 71-76.

MATTHEWS, Wade. Quince segundos para decidirse. La "composición instantánea" y otras ideas recibidas acerca de la improvisación musical. Doce Notas Preliminares. Improvisación, crear en el momento, Madrid, n. 10, pp. 15-39, 2002.

MORO, Daniel. Adolfo Reisin o la democratización de la creación musical. Sul Ponticello. Revista on-line de música y arte sonoro, año 2, n. 15, 2015. Disponible en <http://3epoca.sulponticello.com/adolforeisin-o-la-democratizacion-de-la-creacion-musical/>. Acceso el: 12 jul. 2021.

NOVOA, M. Laura. Cuando el futuro sonaba eléctrico. En: CASTIÑEIRA DE DIOS, José Luis (Dir.). La música en el Di Tella: resonancias de la modernidad. Buenos Aires: Secretaría de Cultura de la Presidencia de la Nación, 2011. pp. 22-29.

PINTA, María Fernanda. Espectáculos y medios audiovisuales en el Di Tella. Tesis de doctorado. Facultad de Filosofía y Letras de la 
El Músico Argentino Adolfo Reisin y las Estéticas de la Improvisación Colectiva Daniel Moro Vallina

Universidad de Buenos Aires, 2010. 382 p. Disponible en <http:// repositorio.filo.uba.ar/handle/filodigital/1666>. Acceso el: 12 feb. 2021.

RIZZARDI, Veniero. Verso un nuovo stile rappresentativo. II teatro mancato e la drammaturgia implicita. En: BORIO, Gianmario, MORELLI, Giovanni y RIZZARDI, Veniero (Eds.). La nuova ricerca sull'opera di Luigi Nono. Firenze: Leo S. Olschki, 1999. pp. 35-51.

TILLET, Agustín. La Cultura como campo de batalla: el PRT-ERP. En: VI Jornadas de Sociología de la Universidad Nacional de La Plata, 2010, La Plata, Argentina. Disponible en <https://www.aacademica. org/000-027/160.pdf>. Acceso el: 26 mar. 2021.

TORTORA, Daniela. Nuova Consonanza. Trent'anni di musica contemporanea in Italia (1959-1988). Lucca: Libreria Musicale Italiana, 1990. 274 p.

VÁZQUEZ, Hernán Gabriel. Apéndice documental: concursos de becarios, docentes, visitantes internacionales y conciertos. En: CASTIÑEIRA DE DIOS, José Luis (Dir.). La música en el Di Tella: resonancias de la modernidad. Buenos Aires: Secretaría de Cultura de la Presidencia de la Nación, 2011. pp. 76-91.

VERZERO, Lorena. Teatro militante. Radicalización artística y política en los años 70. Buenos Aires: Editorial Biblos, 2013. 414 p.

ZIMMERMANN, Susana. Cantos y Exploraciones. Caminos de TeatroDanza. Buenos Aíres: Balletin Dance Ediciones, 2007. 238 p.

\section{Agradecimientos}

Agradecemos especialmente a Stella Maris Prieto Villar, viuda de Adolfo Reisin, el habernos facilitado el acceso al archivo personal del músico y permitirnos tomar fotografía de los documentos que se incluyen en este artículo. 
El Músico Argentino Adolfo Reisin y las Estéticas de la Improvisación Colectiva Daniel Moro Vallina

\section{Publisher}

Universidade Federal de Goiás. Escola de Música e Artes Cênicas. Programa de Pós-graduação em Música. Publicação no Portal de Periódicos UFG.

As ideias expressadas neste artigo são de responsabilidade de seus autores, não representando, necessariamente, a opinião dos editores ou da universidade. 